\section{UNRAVELLING THE ROLE OF CD4+ AND CD8+ T CELLS IN PEMBROLIZUMAB INDUCED MYCOBACTERIUM TUBERCULOSIS GRANULOMA FORMATION IN NASOPHARYNGEAL CARCINOMA}

Tae Yang Desmond Hung*, Ngar Woon Kam, Victor Ho Fun Lee. The University of Hong Kong, Hong Kong, Hong Kong

Background Nasopharyngeal carcinoma (NPC), an endemic disease in Southeast Asia, is characterized by high immune cell infiltration. Pembrolizumab, an immune checkpoint inhibitor that blocks the programmed death-1 (PD-1) surface protein on $\mathrm{CD} 4+$ and CD8 $+\mathrm{T}$ cells and reactivate tumor autoimmunity, ${ }^{1}$ has shown promising results in early NPC trials. ${ }^{2}$ Despite the encouraging results, pembrolizumab induced mycobacterium tuberculosis (MTB) activation/reactivation cases have been reported. $^{3}$ CD4+ T cells play a crucial role initiating MTB granuloma formation through releasing interferon gamma (IFN $\gamma$ ), and the CD4+PD1+ subtype is known to be crucial for controlling MTB infection. ${ }^{3} 4$ Indeed, CD8 $+\mathrm{T}$ cells are believed to play a less important role in MTB immunity. However, the mechanism of pembrolizumab induced MTB granuloma formation remains poorly understood, and the current study objective is to decipher the enigma through investigating the PD-1 and IFN $\gamma$ expression of CD $4+$ and $\mathrm{CD} 8+\mathrm{T}$ cells.

Methods We encountered two NPC patients who suffered from pembrolizumab induced MTB granuloma formation, and their biopsy samples were collected and separated into three groups, malignant, non-malignant and granuloma. The samples were stained with the Opal multiplex immunohistochemistry kit (figure1).

Results The non-malignant group had the highest of amount of $\mathrm{PD}-1+\mathrm{CD} 8+(188.3$ cells/mm2), and the cell density was significantly higher than the malignant group $(2.3$ cells $/ \mathrm{mm} 2$, $\mathrm{p}=0.035)$ and the granuloma group (9 cells $/ \mathrm{mm} 2, \mathrm{p}=0.017)$ (figure 2). Meanwhile, the IFN $\gamma+\mathrm{CD} 8+$ cell density of the granuloma group was the highest $(91.5$ cells $/ \mathrm{mm} 2)$, which was higher than the non-malignant group $(19.3$ cells $/ \mathrm{mm} 2$, $\mathrm{p}=0.020$ ) and the malignant group (56 cells $/ \mathrm{mm} 2 / \mathrm{p}=0.320$ ) (figure 3 ). The cell density of $\mathrm{PD}-1+\mathrm{CD} 4+$ was the highest in the non-malignant group ( 245 cells $/ \mathrm{mm} 2$ ), which was also higher than the malignant group (10.7 cells/mm2, $\mathrm{p}=0.174)$ and the granuloma group ( 35.5 cells $/ \mathrm{mm} 2, \mathrm{p}=0.155)$ (figure 4). Similarly, the cell density of IFN $\gamma+\mathrm{CD} 4+$ (96.5 cells/ $\mathrm{mm} 2$ ) was the highest in granuloma group, which was higher than the malignant group $(26.7$ cells $/ \mathrm{mm} 2, \mathrm{p}=0.550)$ and non-malignant group (15.22 cells $/ \mathrm{mm} 2, \mathrm{p}=0.124)$ (figure 5$)$.

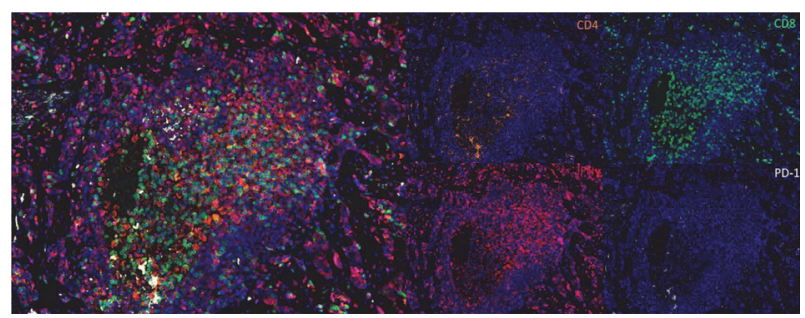

Abstract 305 Figure 1 Multiplex Staining. Staining were performed using Opal multiplex immunohistochemistry staining kit

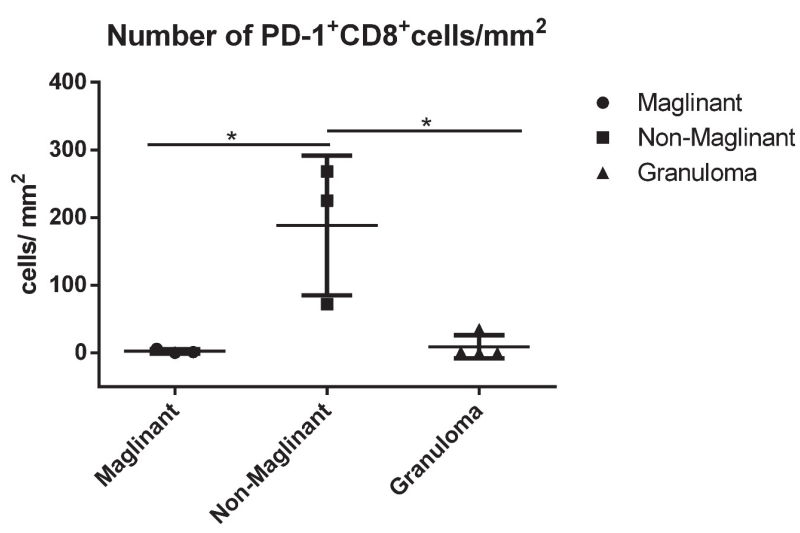

Abstract 305 Figure 2

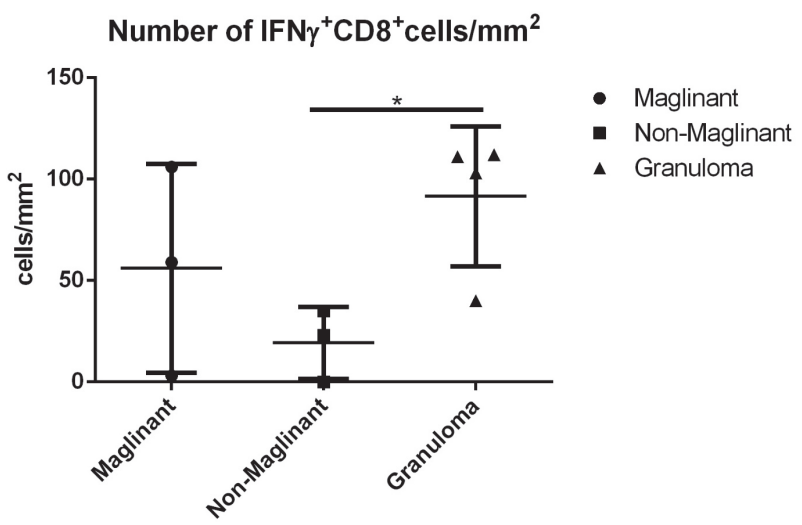

Abstract 305 Figure 3

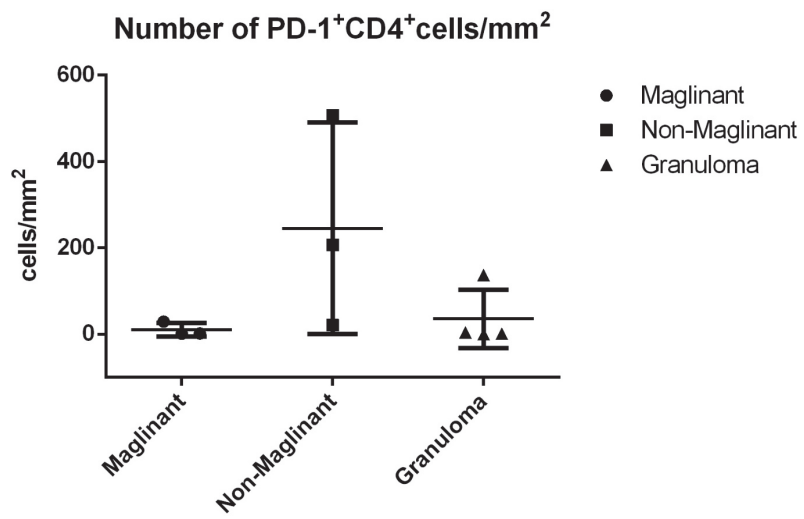

Abstract 305 Figure 4 
Number of IFN $\gamma^{+} \mathrm{CD} 4^{+}$cells $/ \mathrm{mm}^{2}$

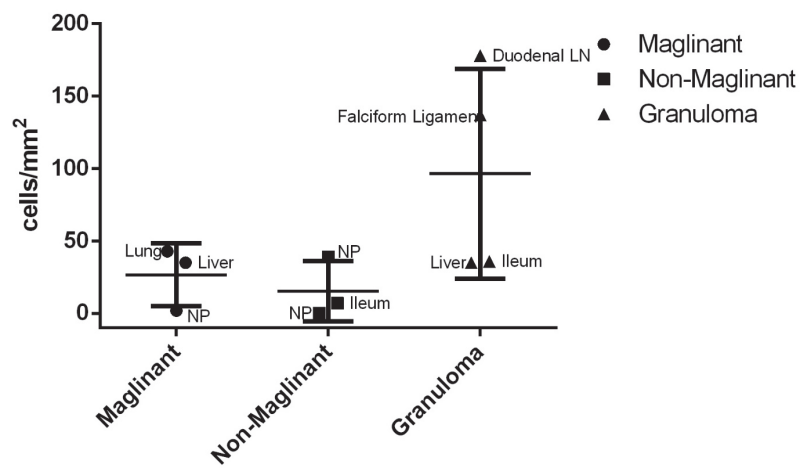

\section{Abstract 305 Figure 5}

Conclusions CD8 + cells displayed more significant PD-1 downregulation and IFN $\gamma$ upregulation in the granuloma group than $\mathrm{CD} 4+$ cells. The significant phenotypical and functionality changes in CD8 + cells might suggest that pembrolizumab could diminish CD4+ cells' role in MTB immunity, which was different from the conventional mechanism in MTB infection. Since IFN $\gamma$ is important for inducing granuloma formation, the increase in IFN $\gamma$ from CD $8+$ cells might provide a logical reason for pembrolizumab induced MTB granuloma formation in NPC patients.

\section{REFERENCES}

1. . Graves $M$, et al. Monitoring patient response to pembrolizumab with peripheral blood exhaustion marker profiles. Front Med (Lausanne) 2019;6:113.

2.. Jain A, Chia WK, Toh HC. Immunotherapy for nasopharyngeal cancer-a review. Chin Clin Oncol 2016;5(2):22.

3.. Barber DL, et al. Tuberculosis following PD-1 blockade for cancer immunotherapy. Sci Transl Med 2019;11(475).

4.. Green AM, Difazio R, Flynn JL. IFN-gamma from CD4 T cells is essential for host survival and enhances CD8 T cell function during mycobacterium tuberculosis infection. J Immunol 2013;190(1):270-7.

http://dx.doi.org/10.1136/jitc-2021-SITC2021.305 